Original Research

\title{
An exploration of individual knowledge and behavior for utilizing OTC drugs and dietary supplements for health enhancement: An empirical analysis from Dubai
}

\author{
Doaa Kamal ALKHALIDI iD, Reem Mohammed JAWAD iD, Maryam Jaffer ALSAMAK (iD, Mai Mohamed AHMED iD, \\ Adeel ASLAM ID
}

Received (first version): 19-Sep-2021 Accepted: 27-Oct-2021 Published online: 29-Oct-2021

\begin{abstract}
Background: Self-medication and acquisition of over-the-counter (OTC) drugs are emerging community health issues. Besides being a cheap alternative for treating common illnesses, the behavior entails serious ramifications, such as medication wastage, increasing pathogen resistance, and adverse drug reactions. So, the purpose of the present study was to explore and understand the consumption of commonly used OTC drugs and dietary supplements in Dubai and also assess individuals' self-care behaviors related to OTC and dietary supplements.

Methodology: A cross-sectional study design was adopted in the present study and 200 participants were included in this study. Data was entered and analyzed through SPSS version 22. While the chi-square test was conducted to find out significance among variables.

Findings: Results from the current study showed that more than a quarter of the participants (31\%) were male and $69 \%$ of them were females. The prevalence of OTC drugs and dietary supplements was higher (98\%) among the individuals living in Dubai. The majority of participants (80\%) used analgesics as OTC drugs. Results also revealed that $35.5 \%$ of participants used vitamins on a daily basis, $11 \%$ used them on weekly basis, and $5.5 \%$ used them on monthly basis. While $79.5 \%$ of participants obtained their OTC drugs and dietary supplements from community pharmacies.

Conclusion: This study provides significant findings regarding an individual's knowledge and behavior for utilizing OTC drugs and dietary supplements. The result has drawn from the present study can help the policymakers, and stakeholders to promulgate and effectiveness of policies and program implementation within the country. Lastly future studies with larger samples are required for the generalizability of the study results.
\end{abstract}

\section{Keywords}

Over-the-count; OTC; Medication; Drugs; Dietary supplements; Health; Vitamins; UAE

\section{INTRODUCTION}

In recent years, over-the-counter (OTC) or non-prescribed medications and health supplements are widely available for citizens worldwide including in the Emirate of Dubai (United Arab Emirates; UAE). ${ }^{1}$ Consumers usually use

Doaa Kamal Alkhalidi*. (Co-corresponding Author). B-Pharm, M.S.C, Ph.D. Assistant Professor in Clinical Pharmacy and Pharmacotherapeutics Department, Dubai Pharmacy College for Girls, Dubai, United Arab Emirates. dr.doaakamal@dpc.edu

Reem Mohammed Jawad. B-Pharm. Registered Pharmacist and graduate of Dubai Pharmacy College for Girls, Aali, Bahrain. Reemalmakana291@hotmail.com

Maryam Jaffer Alsamak. B-Pharm. Registered Pharmacist and graduate of Dubai Pharmacy College for Girls, Manama, Bahrain. mariam.jiff@gmail.com

Mai Mohamed Ahmed. B-Pharm. Registered Pharmacist and graduate of Dubai Pharmacy College for Girls, Doha, Qatar. myooy128@gmail.com

Adeel Aslam** . (Corresponding Author). Pharm-D, Master, Ph.D. Department of Pharmacy Practice, Kulliyyah of Pharmacy, International Islamic University Malaysia, Kuantan 25200, Pahang, Malaysia. adeel.aslam224@gmail. com
OTC drugs and supplements without having prior knowledge about the dosage, drug-drug interactions, and contraindications. While this inappropriate use of OTC drugs and dietary supplements can increase the chances of potential side effects and may harm human health. A recent study had indicated that OTC drugs and supplements used without prescription may cause severe health complications like seizures, anemia, liver and kidney damage, heart attack, stroke, psychiatric problems, allergy, poisoning, disability, and even death. ${ }^{2}$ A study carried out among school students by BarakatHaddad \& Siddiqua, (2018) reported that self-medication consumption with OTC drugs has increased rapidly in $\mathrm{UAE}^{3}$

Analgesics like nonsteroidal anti-inflammatory drugs (NSAIDs) and peripheral analgesics are frequently purchased by adolescent's students in UAE as it is available at a lower cost as compared to prescription drugs. ${ }^{3}$ The high cost of general practitioner (GP) consultation, specialist and routine health check-ups and prescriptions acts as an incentive for the individuals to use OTC drugs reflecting the high prevalence of OTC drug abuse among students in $\mathrm{UAE}^{3} \mathrm{~A}$ recent study conducted by Jairoun et al., (2020) shed light on the fact that sport nutrition supplements are being used by gym users in Dubai, as they believed that these supplements have positive effects on their body in terms of performance, exercise, and dietary supplements make them healthier. ${ }^{4}$ The health 
Alkhalidi DK, Jawad RM, Alsamak MJ, Ahmed MM, Aslam A. An exploration of individual knowledge and behavior for utilizing OTC drugs and dietary supplements for health enhancement: An empirical analysis from Dubai. Pharmacy Practice 2021 Oct-Dec;19(4):2564.

https://doi.org/10.18549/PharmPract.2021.4.2564

or dietary supplements that are added as ingredients in the sports supplements are not substantiated with medical or nutritional value on the label that may cause potential side effects and contraindications. Alhomoud, Basil \& Bondarev, (2016) stated that dietary supplements have substantially increased in the UAE in the last few years. Individuals are purchasing these supplements despite knowing the fact the safety and efficacy of such supplements have not yet been proven. ${ }^{5}$ There is a high prevalence of self-medication of supplements by the students in Dubai believing that it helps to maintain good health and replenish adequate nutrition on a daily basis. ${ }^{4}$ According to Zaghloul et al., (2014) acquisition of OTC drugs and self-medication are emerging in UAE as major health issues. ${ }^{6}$ Individuals are finding OTC drugs as a cheap alternative to treat common illnesses like cold, cough, fever and purchasing products like analgesics, oral care products, antacids, gastrointestinal products, dietary supplements, vitamins, ophthalmic, and feminine care products. It becomes essential for the individuals to have proper knowledge, attitude, and practice (KAP) regarding OTC drugs to prevent risks associated with OTC drugs. ${ }^{7}$

According to Conca \& Worthen, (2012) OTC, drug abuse is a serious global health issue as different classes of therapeutics, numerous dosages, and various drug delivery systems are being implicated in OTC drugs. Individuals who commonly abuse OTC drugs are likely to suffer from various health issues that can have a detrimental effect on their quality of life. ${ }^{8}$ Nonprescription drug abuse can also result in significant mortality and morbidity due to potentially an acute lethal overdose that can require urgent admission to a healthcare facility for treatment and further observation. The recreational abuse of nutritional supplements, vitamins, herbal supplements, and other non-prescribed medications also causes severe complications and death among young abusers and may remain undetected in the absence of interaction with healthcare providers. It has been reported that psychiatric patients may be susceptible to OTC drug abuse such as acetaminophen which is freely available used for committing suicide due to intentional overdose in United States. ${ }^{9}$

According to Khalifeh et al., (2017) self-medication misuse in the Middle East can result in unnecessary and potential health risks for individuals. ${ }^{10}$ Specific medicines like cough syrup, analgesics, antihistamines and antibiotics are available without prescription in Middle East. As discussed previously, consumption of OTC drugs and supplements growing rapidly in the UAE and is expected to continue growing and to have a value of $7 \%$ by $2019 .{ }^{5}$ They could be purchased by the general population without a prescription from pharmacies in UAE. Furthermore, currently, there is a lack of empirical data on the misuse of OTC drugs and dietary supplements in Dubai, UAE. With this view, the present study is intended to estimate the consumption of OTC drugs and dietary supplements in Dubai along with commonly used
OTC drugs. Moreover, the present study is also aimed at assessing the individuals' self-care behaviors related to OTC and dietary supplements.

\section{METHODOLOGY}

\section{Study design and setting}

The present study has adopted a descriptive crosssectional research design. This type of research design has been framed for developing new theories and justifying the present practices in the same manner. The descriptive research design aims to describe the outcomes or observations that have been evolved from the social point of view. The theories evolved from this research design correlate the existing variables in the research and require a descriptive method. Moreover, the present study has followed a deductive research approach (quantitative research design by utilizing deductive reasoning) as this study is determined through the surviving theories that lead towards the analysis of results that have been evolved from the existing theories. The participants included in this study were adults living in Dubai and willing to participate, without having any communication problems either due to illness or some other special reasons.

\section{Sample size}

The sample size was calculated using the single proportion formula without correction for continuity $n=Z^{2} P(1-P) / d^{2}$. At $95 \%$ confidence interval, the $Z$ statistic value is 1.96 , and $P$, the estimated value for the particular indicator was determined to be 0.85 from a pilot study. Assuming a degree of precision (in the proportion of one, $d=0.05$ ), and hence the final sample size (n) was found to be 197, and to make it even total of 200 persons were included in the final study.

\section{Research instrument and data collection}

A pre-validated questionnaire of a previous study was adopted as the study tool. ${ }^{11}$ The questionnaire comprises 24 different questions and it contains both open-ended and close-ended questions. The items in the questionnaire were grouped broadly into the following two categories: (i) sociodemographic characteristics of the participants (age, gender, education, income, nationality, and academic field); (ii) While eighteen questions were about the utilization of OTC drugs and supplements. This study has used the primary data collection method for fulling the major objectives of the study. The primary was obtained by distributing the questionnaire through the survey. The close and open-ended questionnaire is designed keeping in mind the demographic characteristics and related variables that have been tested. The questionnaire was assessed for internal consistency (Cronbach alpha) and reliability (test-retest reliability). According to Sim et al (2016) and Fink (2013) observed that the minimum number of participants for a pilot is 10 , while another study suggested that a pilot study sample should be $10 \%$ 
Alkhalidi DK, Jawad RM, Alsamak MJ, Ahmed MM, Aslam A. An exploration of individual knowledge and behavior for utilizing OTC drugs and dietary supplements for health enhancement: An empirical analysis from Dubai. Pharmacy Practice 2021 Oct-Dec;19(4):2564.

https://doi.org/10.18549/PharmPract.2021.4.2564

of the sample projected for the larger parent study ${ }^{(12-14)}$. So, the sample size for the pilot is 20 and the questionnaire was pilot tested on 20 people to determine questionnaire structure and clarity of language. After the pilot testing of the questionnaire, some necessary changes were highlighted, which were incorporated in the final version of the study instrument.

\section{Data collection}

The data was collected at public places, including shopping malls, supermarkets, public parks, buses, and metro stations. The final version of the questionnaire was used to collect data through the interview administered method from Sep 2019 to Feb 2020. A written signed informed consent form was taken from all participants who agreed to take part in this study. At the same time, an introductory letter was given to all respondents, which included a brief description of the study objectives and their importance. The data was collected through a selfadministered questionnaire by trained interviewers. The confidentiality and anonymity of the participants were protected throughout the study.

\section{Data analysis}

The present study has analyzed the results of the collected data that were collected from the response of the participants with the distribution of questionnaires through surveys. Descriptive analysis and chi-square test have been used for analyzing the collected data.

\section{Ethical approval}

This study was approved by the research ethical committee of Dubai Pharmacy College for Girls in Dubai UAE (RSP-F-01).

\section{RESULTS}

The demographic profile of the participants involves the analysis of age, gender, academic field, and educational level are mentioned in table 1. Results from the current study showed that more than a quarter of the participants (31\%) were male and $69 \%$ of them were females. Most of the participants belonged to the age group of $20-30$ years with $33.5 \%$ while another majority of participants belonged to the age group of $31-40$ years with $32.5 \%$. The majority of the participants $(26 \%)$ belonged to the business field with and $24.5 \%$ belonged to the literature domain, while another major group of participants belonged to the domain of medical with $15 \%$ and $14 \%$ with engineering. Only $12 \%$ of participants were students, while $69 \%$ had completed undergraduate degree/bachelor degree and $13 \%$ were postgraduate.

\section{Reliability}

\section{Internal Consistency and test-retest reliability}

Internal consistency was determined for the questionnaire and Cronbach's alpha was 0.628 . While results obtained

\begin{tabular}{|c|c|c|}
\hline Demographic characteristics & Frequency & Percentage \\
\hline Male & 62 & $31 \%$ \\
\hline Female & 138 & $69 \%$ \\
\hline Age & Frequency & Percentage \\
\hline Below 20 years & 18 & $9 \%$ \\
\hline 20-30 years & 67 & $33.5 \%$ \\
\hline $31-40$ years & 65 & $32.5 \%$ \\
\hline $41-50$ years & 33 & $16.5 \%$ \\
\hline Above 50 years & 17 & $8.5 \%$ \\
\hline Academic field & Frequency & Percentage \\
\hline Housewife & 17 & $8.5 \%$ \\
\hline Business & 52 & $26 \%$ \\
\hline Engineering & 28 & $14 \%$ \\
\hline Medical & 30 & $15 \%$ \\
\hline Arts & 14 & $7 \%$ \\
\hline Literatures & 49 & $24.5 \%$ \\
\hline Students & 10 & $5 \%$ \\
\hline Education level & Frequency & Percentage \\
\hline Students & 24 & $12 \%$ \\
\hline Bachelor & 138 & $69 \%$ \\
\hline Postgraduate & 26 & $13 \%$ \\
\hline Others & 12 & $6 \%$ \\
\hline Total & 200 & $100 \%$ \\
\hline
\end{tabular}

from the test-retest analysis indicate satisfactory reliability and stability and the value for test-retest was $0.71(p<0.05)$.

\section{Prevalence of OTC drugs and dietary supplements}

The prevalence of OTC drugs and supplements among the community of Dubai was $98 \%$ and only $2 \%$ of them were not using OTC drugs. The female gender (68\%) was more prone towards the use of OTC drugs and dietary supplements as compared to males (30\%). Moreover, participants with a bachelor's degree (68.5\%) were most likely to use OTC drugs and dietary supplements. While regarding age groups, the highest prevalence rate was among age groups of $20-30$ years old (33\%) followed by people aged between $31-40$ years old (31.5\%) and $41-50$ years old $(16.5 \%)$. On the other hand, participants having age below 20 years and above 50 years were less likely to practice OTC drugs and dietary supplements $(8.5 \%)$ as compared to other age groups. All the results regarding OTC drugs and dietary supplements are mentioned in table 2.

\section{Commonly used OTC drugs}

The results regarding the most commonly used OTC drugs and dietary supplements among males and females have been also analyzed from the collected data (Figure 
Alkhalidi DK, Jawad RM, Alsamak MJ, Ahmed MM, Aslam A. An exploration of individual knowledge and behavior for utilizing OTC drugs and dietary supplements for health enhancement: An empirical analysis from Dubai. Pharmacy Practice 2021 Oct-Dec;19(4):2564.

https://doi.org/10.18549/PharmPract.2021.4.2564

\begin{tabular}{|c|c|c|c|}
\hline $\begin{array}{l}\text { Demographic } \\
\text { characteristics }\end{array}$ & Yes & No & $p$-value \\
\hline $\begin{array}{l}\text { Gender } \\
\text { Male }\end{array}$ & $30 \%$ & $1 \%$ & \multirow[t]{2}{*}{0.407} \\
\hline Female & $68 \%$ & $1 \%$ & \\
\hline Age & Yes & No & $p$-value \\
\hline Below 20 years & $8.5 \%$ & $0.5 \%$ & \multirow{5}{*}{0.617} \\
\hline $20-30$ years & $33 \%$ & $0.5 \%$ & \\
\hline $31-40$ years & $31.5 \%$ & $1 \%$ & \\
\hline $41-50$ years & $16.5 \%$ & Nil & \\
\hline Above 50 years & $8.5 \%$ & Nil & \\
\hline Academic field & Yes & No & $p$-value \\
\hline Housewife & $8.5 \%$ & $\mathrm{Nil}$ & \multirow{7}{*}{0.159} \\
\hline Business & $15.5 \%$ & $0.5 \%$ & \\
\hline Engineering & $13 \%$ & $1 \%$ & \\
\hline Medical & $15 \%$ & Nil & \\
\hline Arts & $\& \%$ & Nil & \\
\hline Literatures & $24.5 \%$ & Nil & \\
\hline Students & $4.5 \%$ & $0.5 \%$ & \\
\hline Education level & Yes & No & $\mathrm{p}$-value \\
\hline Students & $11.5 \%$ & $0.5 \%$ & \multirow[b]{4}{*}{0.099} \\
\hline Bachelor & $68.5 \%$ & $0.5 \%$ & \\
\hline Postgraduate & $12 \%$ & $1 \%$ & \\
\hline Others & $6 \%$ & Nil & \\
\hline
\end{tabular}

1). It has been found that most of the individuals used analgesics involving $96.8 \%$ of females and $87 \%$ of males. The second major OTC drug and dietary supplements being used were vitamins involving $60 \%$ of females and $60.9 \%$ of males. While OTC drugs against cold and flu were used by a lower number of participants involving $53.2 \%$ of females and $50.7 \%$ of males. Antispasmodics (19.4\% of females and $21 \%$ of males), anti-allergies ( $25.8 \%$ of females and $17.4 \%$ of males), and anti-acids

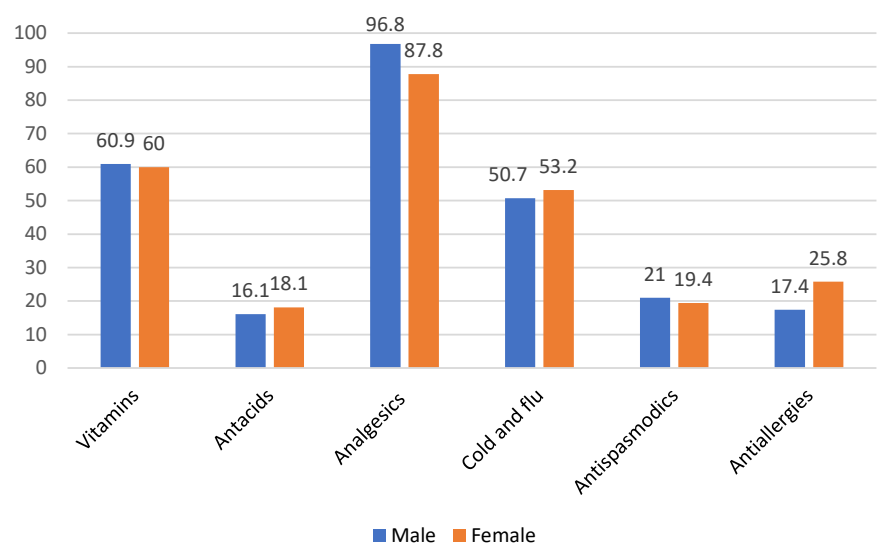

Figure 1. Commonly used OTC drugs and dietary supplements based on gender

( $16.1 \%$ of females and $18.1 \%$ of males) were also used by the individuals.

The pattern of using OTC drugs and dietary supplements

The pattern of using OTC drugs and dietary supplements among males and females was analyzed (Figure 2). Results from the current study revealed that $38.4 \%$ of females used vitamins on a daily basis, $8.7 \%$ used them on weekly

\begin{tabular}{|c|c|c|c|c|}
\hline Criteria & Always & Often & Occasionally & Never \\
\hline Medicine composition & $41.5 \%$ & $18.5 \%$ & $19.5 \%$ & $20.5 \%$ \\
\hline Below 20 years & $0.5 \%$ & $1 \%$ & $2 \%$ & $5.5 \%$ \\
\hline $20-30$ years & $13 \%$ & $6 \%$ & $9.5 \%$ & $5 \%$ \\
\hline $31-40$ years & $16.5 \%$ & $7 \%$ & $3 \%$ & $6 \%$ \\
\hline $41-50$ years & $8 \%$ & $2.5 \%$ & $3 \%$ & $3 \%$ \\
\hline Above 50 years & $2.5 \%$ & $2 \%$ & $2 \%$ & $1 \%$ \\
\hline Indication & $59 \%$ & $19.5 \%$ & $13 \%$ & $8.5 \%$ \\
\hline Below 20 years & $4 \%$ & $2.5 \%$ & $1 \%$ & $1.5 \%$ \\
\hline $20-30$ years & $19.5 \%$ & $8 \%$ & $4.5 \%$ & $1.5 \%$ \\
\hline $31-40$ years & $17.5 \%$ & $6 \%$ & $5.5 \%$ & $3.5 \%$ \\
\hline $41-50$ years & $12 \%$ & $2 \%$ & $1 \%$ & $1.5 \%$ \\
\hline Above 50 years & $6 \%$ & $1 \%$ & $1 \%$ & $0.5 \%$ \\
\hline Dosage & $65.5 \%$ & $14.5 \%$ & $10 \%$ & $10 \%$ \\
\hline Below 20 years & $5.5 \%$ & $1 \%$ & $1 \%$ & $1.5 \%$ \\
\hline $20-30$ years & $21 \%$ & $5 \%$ & $4 \%$ & $3.5 \%$ \\
\hline $31-40$ years & $20.5 \%$ & $5.5 \%$ & $3 \%$ & $3.5 \%$ \\
\hline $41-50$ years & $12.5 \%$ & $2.5 \%$ & $1 \%$ & $0.5 \%$ \\
\hline Above 50 years & $6 \%$ & $0.5 \%$ & $1 \%$ & $1 \%$ \\
\hline Adverse events & $52.5 \%$ & $16.5 \%$ & $17.5 \%$ & $13.5 \%$ \\
\hline Below 20 years & $3 \%$ & $1.5 \%$ & $1.5 \%$ & $3 \%$ \\
\hline $20-30$ years & $17.5 \%$ & $6 \%$ & $6.5 \%$ & $3.5 \%$ \\
\hline $31-40$ years & $16 \%$ & $7.5 \%$ & $4.5 \%$ & $4.5 \%$ \\
\hline $41-50$ years & $11.5 \%$ & Nil & $3 \%$ & $2 \%$ \\
\hline Above 50 years & $4.5 \%$ & $1.5 \%$ & $2 \%$ & $0.5 \%$ \\
\hline Interaction & $35.5 \%$ & $20 \%$ & $19.5 \%$ & $25 \%$ \\
\hline Below 20 years & $1.5 \%$ & $3 \%$ & $0.5 \%$ & $4 \%$ \\
\hline $20-30$ years & $9.5 \%$ & $5.5 \%$ & $9.5 \%$ & $9 \%$ \\
\hline $31-40$ years & $13 \%$ & $6.5 \%$ & $6.5 \%$ & $6.5 \%$ \\
\hline $41-50$ years & $7.5 \%$ & $3.5 \%$ & $2 \%$ & $3.5 \%$ \\
\hline Above 50 years & $4 \%$ & $1.5 \%$ & $1 \%$ & $2 \%$ \\
\hline Contraindication & $46.5 \%$ & $22.5 \%$ & $13 \%$ & $18 \%$ \\
\hline Below 20 years & $3 \%$ & $2 \%$ & $1 \%$ & $3 \%$ \\
\hline $20-30$ years & $15.5 \%$ & $9 \%$ & $3.5 \%$ & $6 \%$ \\
\hline $31-40$ years & $15.5 \%$ & $6.5 \%$ & $5 \%$ & $5.5 \%$ \\
\hline $41-50$ years & $9 \%$ & $3 \%$ & $2.5 \%$ & $2 \%$ \\
\hline Above 50 years & $4 \%$ & $2 \%$ & $1 \%$ & $1.5 \%$ \\
\hline Mode of storage & $40.5 \%$ & $13 \%$ & $19 \%$ & $27.5 \%$ \\
\hline Below 20 years & $3 \%$ & Nil & $2 \%$ & $4 \%$ \\
\hline 20-30 years & $10 \%$ & $6 \%$ & $8 \%$ & $9.5 \%$ \\
\hline $31-40$ years & $16 \%$ & $5 \%$ & $3 \%$ & $8.5 \%$ \\
\hline $41-50$ years & $8 \%$ & $1 \%$ & $4.5 \%$ & $3 \%$ \\
\hline Above 50 years & $3.5 \%$ & $1 \%$ & $1.5 \%$ & $2.5 \%$ \\
\hline
\end{tabular}


Alkhalidi DK, Jawad RM, Alsamak MJ, Ahmed MM, Aslam A. An exploration of individual knowledge and behavior for utilizing OTC drugs and dietary supplements for health enhancement: An empirical analysis from Dubai. Pharmacy Practice 2021 Oct-Dec;19(4):2564.

https://doi.org/10.18549/PharmPract.2021.4.2564

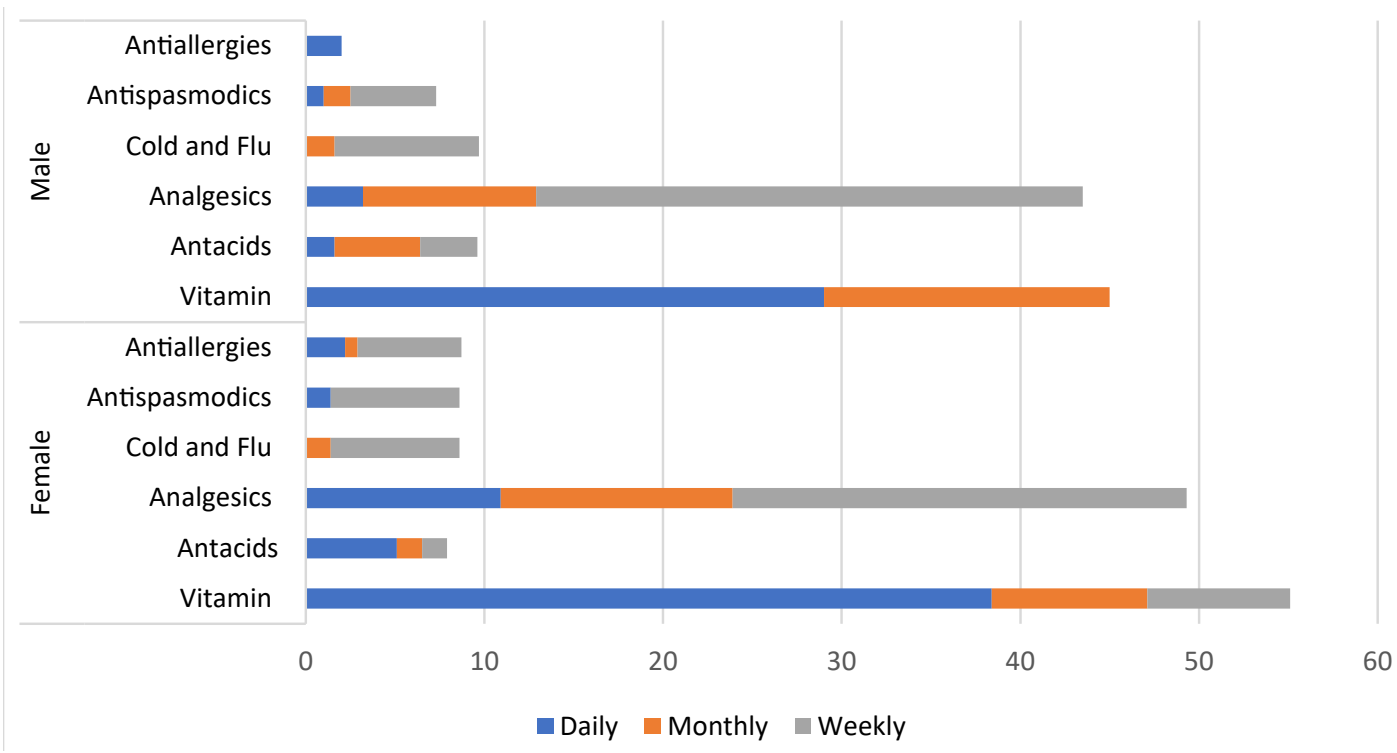

Figure 2. Pattern of using OTC drugs and dietary supplements among males and females

\begin{tabular}{|l|l|c|}
\hline \multicolumn{3}{|l}{ Table 4. Criteria affecting the participants choice of OTC drugs and } \\
dietary supplements & Academic field groups & Percentage \\
\hline Criteria & Literature- high & $65.3 \%$ \\
\hline Physician advice & Arts-low & $14.3 \%$ \\
\hline Pharmacist advice & Housewife-high & $41.2 \%$ \\
& Business-low & $9.6 \%$ \\
\hline Traditional & Housewife-high & $11.8 \%$ \\
advertisement & Business-low & $40.4 \%$ \\
\hline Social media & Housewife-high & $11.8 \%$ \\
advertisement & Arts-low & $42.9 \%$ \\
\hline Dosage form & Housewife-high & $35.3 \%$ \\
& Student-low & $30 \%$ \\
\hline Family, friend's opinion & Housewife-high & $35.3 \%$ \\
& Student-low & $20 \%$ \\
\hline Own experience & Medical -high & $63.3 \%$ \\
& Business-low & $7.7 \%$ \\
\hline price & Housewife-high & $35.3 \%$ \\
& Student-low & $20 \%$ \\
\hline
\end{tabular}

basis, and $1.4 \%$ used them on a weekly and monthly basis. Regarding the interpretation of males, results showed that analgesics were the most commonly used medication and dietary supplements by the males with $30.6 \%$ being used on a monthly basis. While only $9.7 \%$ used them weekly and $3.2 \%$ used them on daily basis. The second common group of medication and dietary supplements involves the vitamins mostly used on daily basis with $29 \%$ and $16 \%$ males used them on weekly

basis, and $85 \%$ used them on monthly basis. Analgesics were another major group of OTC drugs that were used by females mostly on monthly basis (25.4\%). While $13 \%$ of females used analgesics on weekly basis and $10.9 \%$ on daily basis. Cold and flu and antispasmodic medication were used by $7.2 \%$ of females on monthly basis. While $1.4 \%$ used cold and flu medications on weekly basis and the same percentage used antispasmodic medications on daily basis. Anti-allergies were the least used medication by the females with mostly $5.8 \%$ used them on monthly basis, $2.2 \%$ on daily basis, and only $0.7 \%$ on weekly basis. Furthermore, $5.1 \%$ of females used antiacids on daily

\begin{tabular}{|c|c|c|}
\hline \multicolumn{3}{|c|}{$\begin{array}{l}\text { Table 5.Chi-square test of significance for frequent and } \\
\text { most commonly used OTC drugs and dietary supplements } \\
\text { among males and females }\end{array}$} \\
\hline Parameter & Chi-square value & P-value \\
\hline Vitamins & 9.025 & 0.029 \\
\hline Antacids & 3.935 & 0.269 \\
\hline Analgesics & 4.054 & 0.256 \\
\hline Cold and Flu & 0.05 & 0.975 \\
\hline Anti-spasmodic & 1.058 & 0.589 \\
\hline Anti-allergies & 4.37 & 0.224 \\
\hline \multicolumn{3}{|c|}{$\begin{array}{l}\text { Chi-square test of significance for commonly used OTC } \\
\text { drugs and dietary supplements }\end{array}$} \\
\hline Parameter & Chi square value & $P$ value \\
\hline Vitamins & 1.505 & 0.22 \\
\hline Antacids & 0.117 & 0.732 \\
\hline Analgesics & 4.582 & 0.032 \\
\hline Cold and Flu & 0.107 & 0.743 \\
\hline Anti-spasmodic & 0.072 & 0.788 \\
\hline Anti-allergies & 1.893 & 0.169 \\
\hline
\end{tabular}


Alkhalidi DK, Jawad RM, Alsamak MJ, Ahmed MM, Aslam A. An exploration of individual knowledge and behavior for utilizing OTC drugs and dietary supplements for health enhancement: An empirical analysis from Dubai. Pharmacy Practice 2021 Oct-Dec;19(4):2564.

https://doi.org/10.18549/PharmPract.2021.4.2564

basis. Cold and flu were used mostly on monthly basis with $8.1 \%$, and $1.6 \%$ on weekly basis. Lastly, Anti-acids were used mostly on weekly basis with $4.8 \%, 3.2 \%$ on a monthly basis, and $1.6 \%$ on daily basis. None of the males used anti-allergies as OTC drugs.

\section{Participant's referral to the medication leaflet}

Results showed that before buying OTC drugs and supplements the majority of the participants always read leaflet to know about dosage form (65.5\%), followed by indication (59\%), adverse events $(52.2 \%)$, contraindications (46.5\%), medicine composition (41.5\%), mode of storage (40.5\%) and interaction (30.5\%). On the other hand, $27.5 \%$ of participants said that they never read any information from leaflet regarding mode of storage followed by interaction (25\%), medicine composition $(20.5 \%)$, contraindication (18\%), adverse events $(13.5 \%)$, dosage (10\%) and indication (8.5\%). Results regarding referral to the medication leaflet content before taking the OTC drugs and dietary supplements with respect to age groups are mentioned in table 3.

\section{Criteria affecting the participants choice of OTC drugs and dietary supplements}

Various criteria affecting the patient's choice of medication and dietary supplements based were also analyzed and results indicate that most of the participants belonged to the literature field (65.3\%) preferred physician advice while choosing OTC drugs and dietary supplements. While all results regarding criteria affecting the patient's choice of OTC drugs and dietary supplements are mentioned in table 4.

\section{Common sources of obtaining OTC drugs and dietary supplements}

Among the participants, the majority of participants who had OTC drugs and dietary supplements obtained their antibiotics from community pharmacies $79.5 \%$, while $12 \%$ of participants obtained their OTC drugs from supermarkets. At the same time, $5.5 \%$ of participants obtained their OTC drugs and dietary supplements from an online herbal medical shop and only $3.5 \%$ buy them from an online pharmacy (Figure 3).

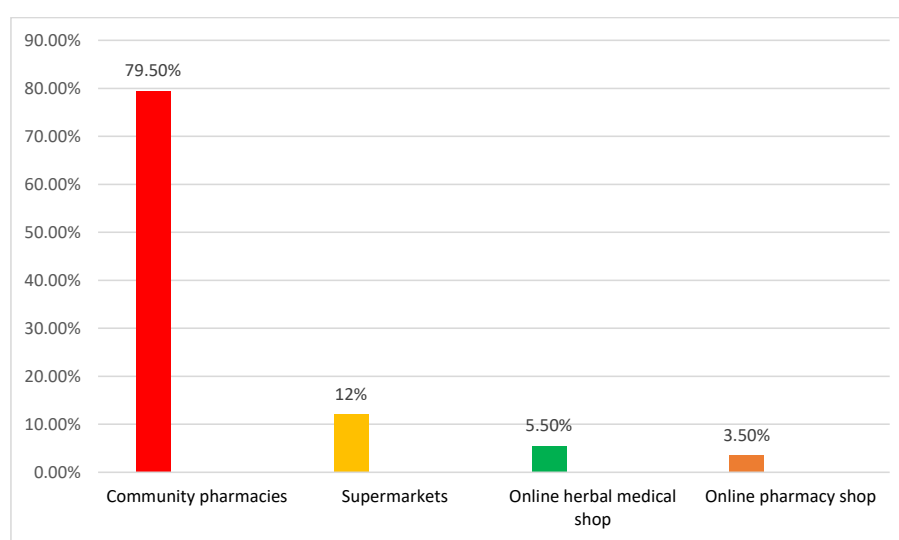

Figure 3. Common sources of obtaining OTC drugs and dietary supplements

\begin{tabular}{|l|c|c|}
\hline \multicolumn{3}{|l|}{ Table 6. Participant's knowledge between different age groups } \\
\hline Parameter & Chi-square value & P-value \\
\hline Medicine composition & 31.554 & 0.002 \\
\hline Indication & 10.461 & 0.576 \\
\hline Dosage & 5.47 & 0.94 \\
\hline Adverse events & 17.990 & 0.116 \\
\hline Interaction & 16.406 & 0.173 \\
\hline Contraindication & 6.059 & 0.913 \\
\hline Mode of storage & 17.372 & 0.136 \\
\hline
\end{tabular}

Note: $p<0.05$ Significant

\begin{tabular}{|l|c|c|}
\hline $\begin{array}{l}\text { Table 7. Criteria affecting the participants choice of } \\
\text { medications and dietary supplements }\end{array}$ \\
\hline Parameter & Chi-square value & P-value \\
\hline Physician advice & 30.147 & 0.180 \\
\hline Pharmacist advice & 20.765 & 0.653 \\
\hline Traditional advertisement & 17.837 & 0.811 \\
\hline Social media advertisement & 23.27 & 0.504 \\
\hline Dosage form & 20.374 & 0.675 \\
\hline Family, friend's opinion & 20.427 & 0.672 \\
\hline Own experience & 25.236 & 0.393 \\
\hline price & 21.277 & 0.622 \\
\hline
\end{tabular}

Note: $p<0.05$ Significant

\section{Side effects and action was taken after using OTC drugs} and dietary supplements

The participant's experienced side effects and their actions have been also analyzed. It has been found that almost $70.5 \%$ of the individuals have not experienced any side effects while $29.5 \%$ of them have experienced some of the side effects. Regarding the participant's action towards the developed side effect of OTC drugs and dietary supplements, it has been found that around 83 $\%$ of them have stopped the medication. Approximately, $17 \%$ of them reduced the dosage of medication while none of the participants continued with the medication.

Chi-square test of significance for frequent and most commonly used OTC drugs and dietary supplements

The frequency of use of common OTC drugs and dietary supplements was analyzed for significance. The chisquare value for vitamins was 9.025 and the $p$-value was 0.029 which is less than or equal to the significance level of 0.05 . Hence, it was observed that vitamins were statistically significant between the males and females when compared with the use of antacids, analgesics, cold and flu, antispasmodics, and anti-allergies. The frequency of use of Antacids, analgesics, cold and flu, anti-spasmodic, and anti-allergies between males and females was not statistically significant. The significant level with the variables was analyzed for the present 
Alkhalidi DK, Jawad RM, Alsamak MJ, Ahmed MM, Aslam A. An exploration of individual knowledge and behavior for utilizing OTC drugs and dietary supplements for health enhancement: An empirical analysis from Dubai. Pharmacy Practice 2021 Oct-Dec;19(4):2564.

https://doi.org/10.18549/PharmPract.2021.4.2564

study and results are mention in table 5 . The results revealed that the use of common OTC drugs and dietary supplements had a significant difference for analgesics, but no significant difference was noted for Vitamins, antacids, Cold and flu, anti-spasmodic, and anti-allergies. In this analysis for analgesics, the chi-square value was 4.582 and the p-value was 0.032 which is less than or equal to the significance level of 0.05 .

\section{Participants knowledge regarding OTC drugs and dietary supplements between different age groups}

The percentage of patient's knowledge between different age groups was also analyzed and results are mentioned in table 6 . The percentage of patient's knowledge regarding medicine composition was statistically significant between different age groups as it showed the chi-value of 31.554 and p-value of 0.002 which is less than the significant level of 0.05. But there was no statistically significant difference for indication, dosage, adverse events, interaction, contraindication, and mode of storage as the $p$-value is larger than the significant level.

\section{Criteria affecting the participants choice of OTC drugs and dietary supplements}

The criteria affecting the patients' choice of medications and dietary supplements were analyzed and results are mentioned in table 7 . It was observed that the criteria affecting the patient's choice of medications and dietary supplements were not statistically significant with physician's advice, pharmacist advice, traditional advertisement, social media advertisement, dosage form, family, friend's opinion, own experience, and price as the p-value was larger than the significant level. Moreover, results also showed that the choice of OTC drugs and dietary supplements was largely based on participants with prior knowledge (54.4\%). While $40.5 \%$ chose OTC drugs and dietary supplements that are well-known and approved.

\section{DISCUSSION}

The present study has analyzed the results of collected data for describing the outcomes or observations that have been evolved from the social point of view. The results from the current study showed a high prevalence of OTC drugs and dietary supplements (98\%). A study performed in Cyprus also showed similar results, where 97\% consumed OTC drugs. ${ }^{15}$ Previous studies performed in Spain (78.9\%), the Czech Republic (92\%) and Sweden $(87 \%)$ showed that a lower number of people used OTC drugs than current study. ${ }^{2,15,16}$ The high prevalence of OTC drugs in the current study might be due to cultural diversity. There are many different ethnicities in the UAE, whereas the population is composed of around $20 \%$ as UAE nationals and the reminders are expatriates. ${ }^{17}$ All UAE nationals have the healthcare and medications free of charge, while the expatriates have plans of health insurance as it can vary from full coverage to copayment based on the type of the insurance plan. ${ }^{6}$ This payment can be considered as a factor to avoid visiting the physicians and preferring to use OTC drugs. Most of the participants from current study purchased their OTC drugs and dietary supplements form pharmacies and some other studies also showed similar results. ${ }^{18,19}$ Moreover, results from the current study also revealed that females (students and housewives) are most prone towards the use of OTC drugs, and these findings are confirmed by other studies as well. ${ }^{20-22}$

In addition to this, the results from the present study also revealed that females used OTC drugs and supplements on daily basis to maintain good health. A study performed among students showed a high prevalence of selfmedication of supplements among the students was noted in Dubai believing that it helps to maintain good health and replenish adequate nutrition on a daily basis. ${ }^{4}$ Analgesics are the most commonly used drugs and it is a prominent factor influencing the use of these drugs internationally. ${ }^{23}$ Therefore, the analgesic segment had the highest share of the UAE market in the OTC drugs especially among the expatriate. ${ }^{6}$ Results from the present study also revealed that the majority of participants used analgesics (96.80\%). The consumption of analgesics in the present study, was higher than that reported in the United States of America (63\%). ${ }^{24} \mathrm{~A}$ study performed in the UAE also showed that vitamins are frequently used as dietary supplements by individuals. ${ }^{5}$ Another important aspect is the effect of choice of OTC drugs and the information provided through media ${ }^{25}$ and physician advice. A total of $79.6 \%$ of the participants from the current study preferred physician advice while purchasing OTC drugs and dietary supplements. Moreover, results from the present study also indicate that participant's knowledge regarding the choice of OTC drugs and dietary supplements also played an important role. The existing literature has justified this fact by stating the safe use of OTC drugs with selfmedication as per the individuals' knowledge, attitude, and practice (KAP) influences the appropriate choice of medication and such practice prevent risks associated with OTC and dietary supplements. ${ }^{7}$ Hence, there is a need for improved knowledge of individuals towards self-medication behavior to preserve their health. This study has several limitations, as the present study has acknowledged the response towards individual's knowledge and practices on consumption and utility of OTC drugs and dietary supplements and hence, cannot be completely represented for the whole population from the Dubai region. As the statistical reasoning applies to the studied group, the derived conclusions revealed that individuals must take caution while using the OTC drugs and dietary supplements as most of the variations are evolved according to the gender, their age group, and academic field. Therefore, the present study should be considered as the empirical study of individuals' 
Alkhalidi DK, Jawad RM, Alsamak MJ, Ahmed MM, Aslam A. An exploration of individual knowledge and behavior for utilizing OTC drugs and dietary supplements for health enhancement: An empirical analysis from Dubai. Pharmacy Practice 2021 Oct-Dec;19(4):2564.

https://doi.org/10.18549/PharmPract.2021.4.2564

knowledge regarding their health impact towards the use of OTC drugs and dietary supplements and its findings and conclusions have to be treated as empirical only. Lastly, this study used a convivence sampling method so the results of the current study cannot be generalized to the whole population of Dubai.

\section{CONCLUSION}

The present study has revealed the fact that OTC drugs and dietary supplements consumption in Dubai among different participants was high and reached 98\%. In addition, the most commonly used OTC drugs was analgesics. Furthermore, our study concluded that the majority of participants that trusted the medical staff consultation were between the ages of 20-40 years and they were not influenced by social media and traditional media (TV, Radio) advertisement. Regarding the safetyrelated issue, the majority of people were aware of how serious the side effects of these medications could affect their overall health, so their action was rational as they would immediately recognize the effect, stop the medication and seek medical advice. Although OTC drugs have a high safety margin, that does not justify their irrational consumption. The awareness program regarding the safe use of OTC drugs should be implemented through healthcare professionals especially through pharmacists, as patient safety is one of the main concerns.

\section{ACKNOWLEDGEMENT}

The authors acknowledge B.T for adopting their study instrument. In addition, we would like to thank the pharmacist Rana Kamel for her help in the data collection.

\section{CONFLICTS OF INTEREST}

Authors declare that they have no conflicts of interest to disclose.

\section{FUNDING}

No funding received for this research.

\section{AUTHOR ROLES (CRediT)}

Conceptualization: DKA.

Data curation: RMJ, MJA, MMA

Formal analysis: RMJ, MJA, MMA. A.D

Investigation: RMJ, MJA, MMA

Project administration: DKA.

Supervision: DKA.

Writing - original draft: RMJ, MJA, MMA

Writing - review \& editing: DKA. AD.

\section{References}

1. Abdulla NM, Aziz F, Blair I, et al. Prevalence of, and factors associated with health supplement use in Dubai, United Arab Emirates: a population-based cross-sectional study. BMC Complement Alt Med Rev. 2019;19(1):1-11. https://doi.org/10.1186/ s12906-019-2593-6

2. Sánchez-Sánchez E, Fernández-Cerezo FL, Díaz-Jimenez J, et al. Consumption of over-the-Counter Drugs: Prevalence and Type of Drugs. Int J Environ Res Public Health. 2021;18(11):5530. https://doi.org/10.3390/ijerph18115530

3. Barakat-Haddad C, Siddiqua A. Prevalence and predictors of over-the-counter medication use among adolescents in the United Arab Emirates. East Mediterr Health J. 2018;23(11):744-753. https://doi.org/10.26719/2017.23.11.744

4. Jairoun AA, Al-Hemyari SS, Shahwan M, et al. What are the beliefs and behaviours related to sport nutrition supplements, particularly regarding UAE regulatory issues, among male fitness centre members in Dubai? Clin Epidemiol Glob Health. 2020;8(3):934-938. https://doi.org/10.1016/i.cegh.2020.02.027

5. Alhomoud FK, Basil M, Bondarev A. Knowledge, Attitudes and Practices (KAP) Relating to Dietary Supplements Among Health Sciences and Non-Health Sciences Students in One of The Universities of United Arab Emirates (UAE). J Clin Diagn Res. 2016;10(9):JC05-JC9. https://doi.org/10.7860/icdr/2016/19300.84391

6. Zaghloul AA, Elsergany M, El-Enein NA, et al. Over-the-counter medication patterns in households in Sharjah, United Arab Emirates. Risk Manag Healthc Policy. 2013;7:19-24. https://doi.org/10.2147/rmhp.s55752

7. Bekele KM, Abay AM, Mengistu KA, et al. Knowledge, Attitude, and Practice on Over-the-Counter Drugs Among Pharmacy and Medical Students: A Facility-Based Cross-Sectional Study. Integr Pharm Res Pract. 2020;9:135-146. https://doi.org/10.2147/ iprp.s266786

8. Conca AJ, Worthen DR. Nonprescription drug abuse. J Pharm Pract. 2012;25(1):13-21. https://doi. org/10.1177/0897190011431148

9. Benotsch EG, Koester S, Martin AM, et al. Intentional misuse of over-the-counter medications, mental health, and polysubstance use in young adults. J Community Health Nurs. 2014;39(4):688-695. https://doi.org/10.1007/s10900-013-9811-9

10. Khalifeh MM, Moore ND, Salameh PR. Self-medication misuse in the Middle East: a systematic literature review. Pharma Res Perspect. 2017;5(4). https://doi.org/10.1002/prp2.323

11. Bochenek T, Godman B, Lipowska K, et al. Over-the-counter medicine and dietary supplement consumption among academic youth in Poland. Expert Rev Pharmacoecon Outcomes Res. 2016;16(2):199-205. https://doi.org/10.1586/14737167.2016.11 54790 
Alkhalidi DK, Jawad RM, Alsamak MJ, Ahmed MM, Aslam A. An exploration of individual knowledge and behavior for utilizing OTC drugs and dietary supplements for health enhancement: An empirical analysis from Dubai. Pharmacy Practice 2021 Oct-Dec;19(4):2564.

https://doi.org/10.18549/PharmPract.2021.4.2564

12. Sim J, Saunders B, Waterfield J, et al. Can sample size in qualitative research be determined a priori? International Journal of Social Research Methodology. 2018;21(5):619-634. https://doi.org/10.1080/13645579.2018.1454643

13. Fink A. How to conduct surveys: A step-by-step guide: Sage Publications; 2015.

14. Connelly LM. Pilot studies. Medsurg Nurs. 2008;17(6):411.

15. Kamekis A, Bertsias A, Moschandreas J, et al. Patients' intention to consume prescribed and non-prescribed medicines: $A$ study based on the theory of planned behaviour in selected European countries. J Clin Pharm Ther. 2018;43(1):26-35. https:// doi.org/10.1111/icpt.12601

16. Hedenrud T, Andersson Sundell K, Martinsson J, et al. Attitudes towards sales and use of over-the-counter drugs in Sweden in a reregulated pharmacy market: a population-based study. Int J Pharm Pract. 2019;27(1):17-24. https://doi.org/10.1111/ iipp.12457

17. Hamoudi, R., Saheb Sharif-Askari, N., Saheb Sharif-Askari, F. et al. Prediabetes and diabetes prevalence and risk factors comparison between ethnic groups in the United Arab Emirates. Sci Rep 9, 17437 (2019). https://doi.org/10.1038/s41598019-53505-7

18. Abduelkarem AR, Mustafa H. Use of over-the-counter medication among pregnant women in Sharjah, United Arab Emirates. J Pregnancy. 2017:2017. https://doi.org/10.1155/2017/4503793

19. Luketina-Sunjka M, Rancic N, Mihailovic N, et al. The impact of the socio-demographic characteristics of complementary and alternative medicine users in Serbia on OTC drug consumption. Front Public Health. 2019;7:303. https://doi.org/10.3389/ fpubh.2019.00303

20. Brandão GR, Teixeira L, Araújo L, et al. Self-medication in older European adults: Prevalence and predictive factors. Arch Gerontol Geriatr. 2020;91:104189. https://doi.org/10.1016/i.archger.2020.104189

21. Hansen $E H$, Holstein BE, Due $P$, et al. International survey of self-reported medicine use among adolescents. Ann Pharmacother. 2003;37(3):361-366. https://doi.org/10.1345/aph.1c111

22. Wilcox CM, Cryer B, Triadafilopoulos G. Patterns of use and public perception of over-the-counter pain relievers: focus on nonsteroidal antiinflammatory drugs. J Rheumatol. 2005;32(11):2218-2224.

23. Carrasco-Garrido P, de Andrés AL, Barrera VH, et al. Predictive factors of self-medicated analgesic use in Spanish adults: a cross-sectional national study. BMC pharmacology \& toxicology. 2014;15:36. https://doi.org/10.1186/2050-6511-15-36

24. Cryer B, Barnett MA, Wagner J, et al. Overuse and misperceptions of nonsteroidal anti-inflammatory drugs in the United States. Am J Med Sci. 2016;352(5):472-480. https://doi.org/10.1016/i.amjms.2016.08.028

25. Yousaf A, Hagen R, Delaney E, et al. The influence of social media on acne treatment: A cross-sectional survey. Pediatr Dermatol. 2020;37(2):301-304. https://doi.org/10.1111/pde.14091 